Fermilab-TM-2377

\title{
Tritium Transport in the NuMI Decay Pipe Region - Modeling and Comparison with Experimental Data
}

\author{
J. Hylen and R. Plunkett \\ 3 May, 2007
}

\section{Introduction}

The NuMI (Neutrinos at Main Injector) beam facility at Fermilab is designed to produce an intense beam of muon neutrinos to be sent to the MINOS underground experiment in Soudan, Minnesota. Neutrinos are created by the decay of heavier particles. In the case of NuMI, the decaying particles are created by interaction of high-energy protons in a target, creating mostly positive pions. These particles can also interact with their environment, resulting in production of a variety of short-lived radionuclides and tritium.

In the NuMI beam, neutrinos are produced by $120 \mathrm{GeV}$ protons from the Fermilab Main Injector accelerator which are injected into the NuMI beam line using single turn extraction. The beam line has been designed for $400 \mathrm{~kW}$ beam power, roughly a factor of 2 above the initial (2005-06) running conditions.

Extracted protons are bent downwards at a 57mr angle towards the Soudan Laboratory. The meson production target is a $94 \mathrm{~cm}$ segmented graphite rod, cooled by water in stainless tubes on the top and bottom of the target. The target is followed by two magnetic horns which are pulsed to $200 \mathrm{kA}$ in synchronization with the passage of the beam, producing focusing of the secondary hadron beam and its daughter neutrinos.

Downstream of the second horn the meson beam is transported for $675 \mathrm{~m}$ in an evacuated 2 m diameter beam (“decay”) pipe. Subsequently, the residual mesons and protons are absorbed in a water cooled aluminum/steel absorber immediately downstream of the decay pipe. Some $200 \mathrm{~m}$ of rock further downstream ranges out all of the residual muons.

During beam operations, after installation of the chiller condensate system in December 2005, the concentration of tritiated water in the MINOS sump flow of $177 \mathrm{gpm}$ was around $12 \mathrm{pCi} / \mathrm{ml}$, for a total of $0.010 \mathrm{pCi} /$ day. A simple model of tritium transport and deposition via humidity has been constructed to aid in understanding how tritium reaches the sump water. The model deals with tritium transported as HTO, water in which one hydrogen atom has been replaced with tritium. Based on concepts supported by the modeling, a dehumidification system was installed during May 2006 that reduced the tritium level in the sump by a factor of two. 
This note is primarily concerned with tritium that was produced in the NuMI target pile, carried by air flow into the target hall and down the decay pipe passageway (where most of it was deposited). The air is exhausted through the existing air vent shaft EAV2 (Figure 1).

\section{Layout of the relevant NuMI beam-line areas}

In the NuMI target pile, air is recirculated from the central beam "chase” (centered on the Horn in Figure 2) through external chiller coils (where some water is condensed and collected) and back to the target through the space between the steel shielding and surrounding concrete, which forms the floor, walls, and cover of the shielded region The adjacent utility rooms (Figure 3) are maintained at a slight overpressure relative to the target hall, so that air leaking from the target pile into the target hall is carried down the passageway next to the decay pipe (Figure 4). An essential feature of the design is that the transit time for air through the decay pipe passageway gives short-lived radionuclides time to decay before being released to the outside air. Figure 5 shows schematically how desiccant units were added to intercept the tritium-carrying humidity, while allowing the short-lived radio-nuclides to proceed down the decay pipe passageway.

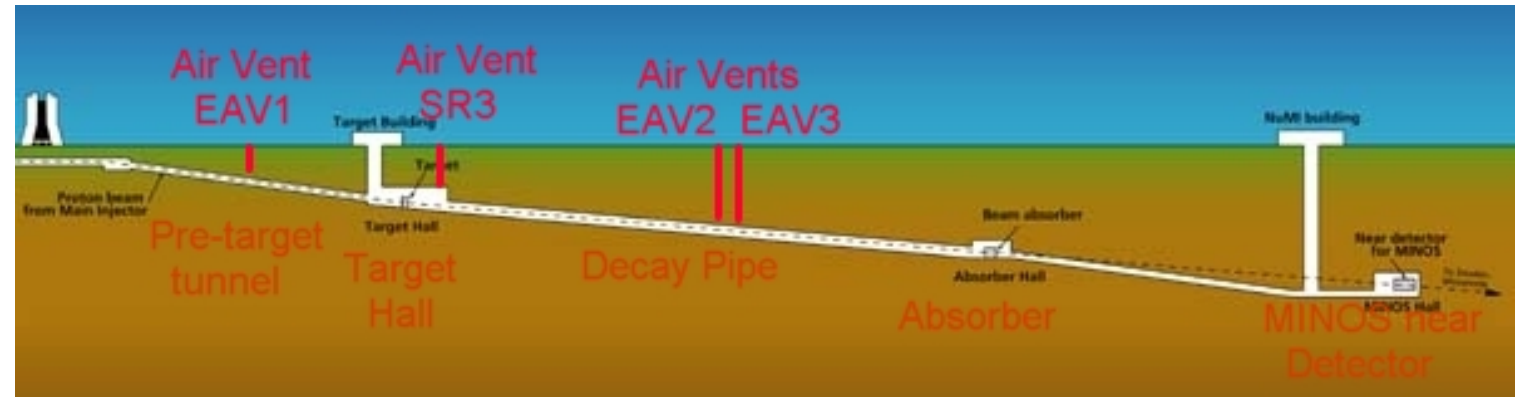

Figure 1 Layout of the NuMI beam-line, showing air vents. 


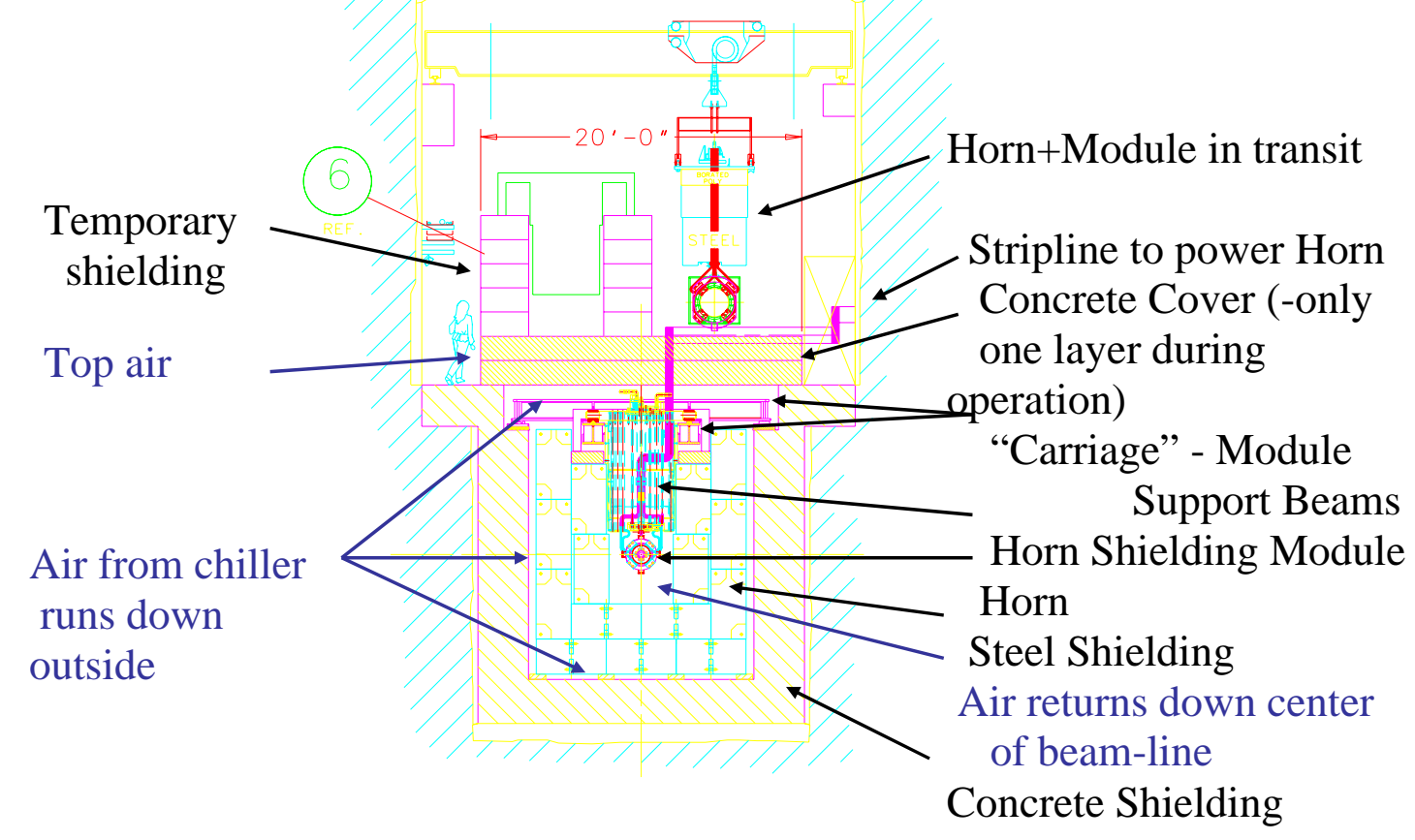

Figure 2 Target hall cross section.

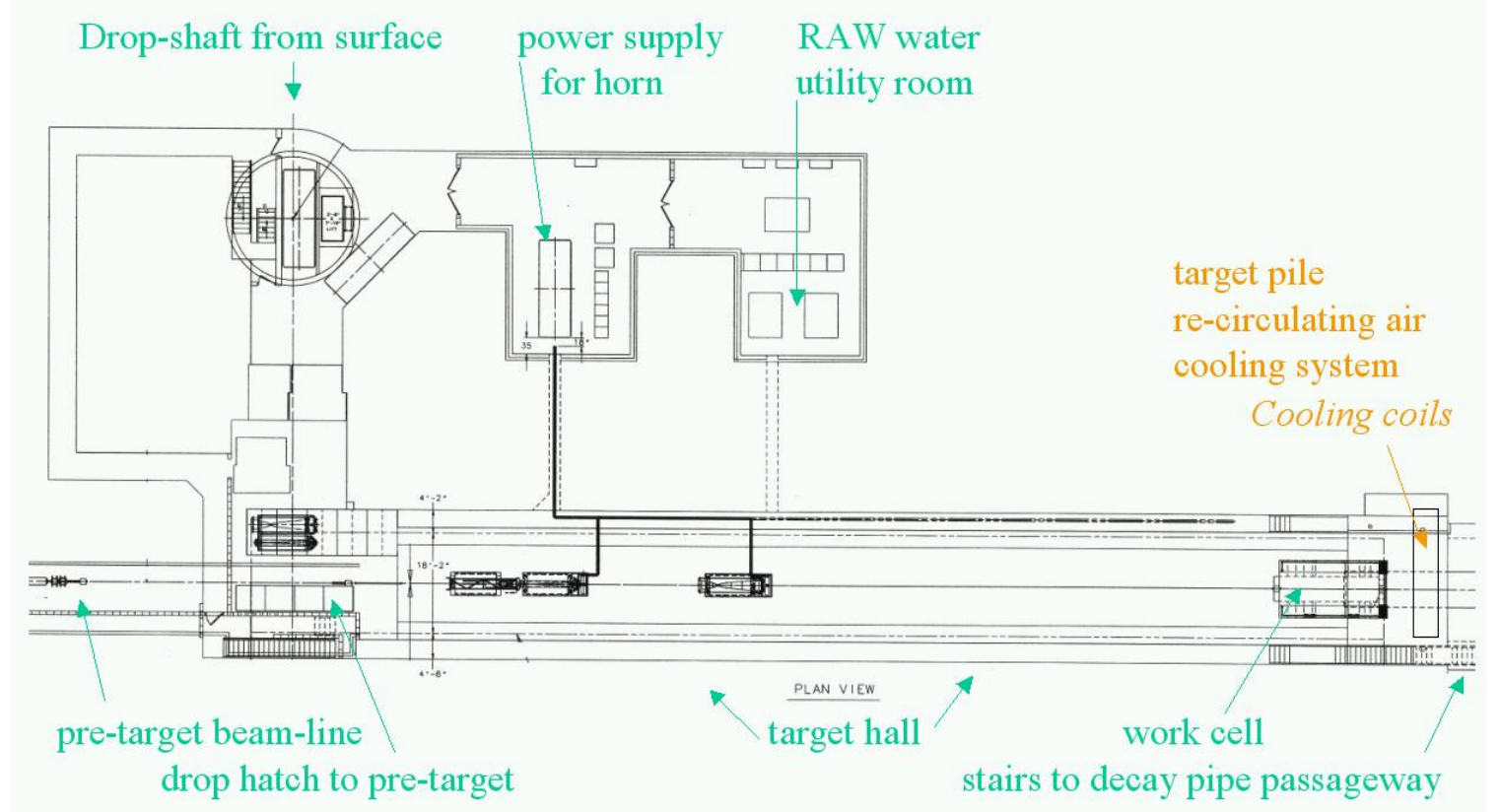

Figure 3 Plan view of target hall and support rooms. 


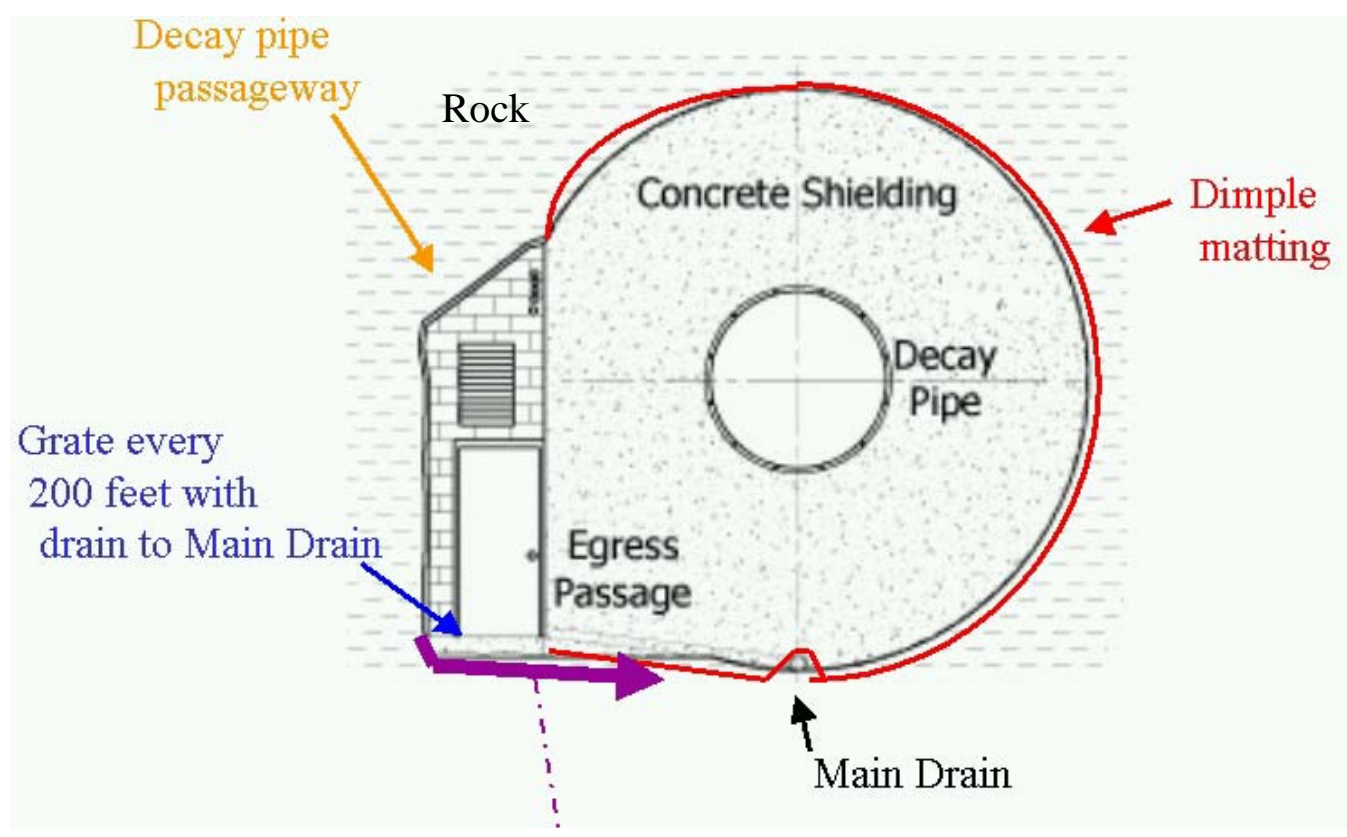

Figure 4 Cross section of decay pipe, concrete shielding, and passageway to left of decay pipe.

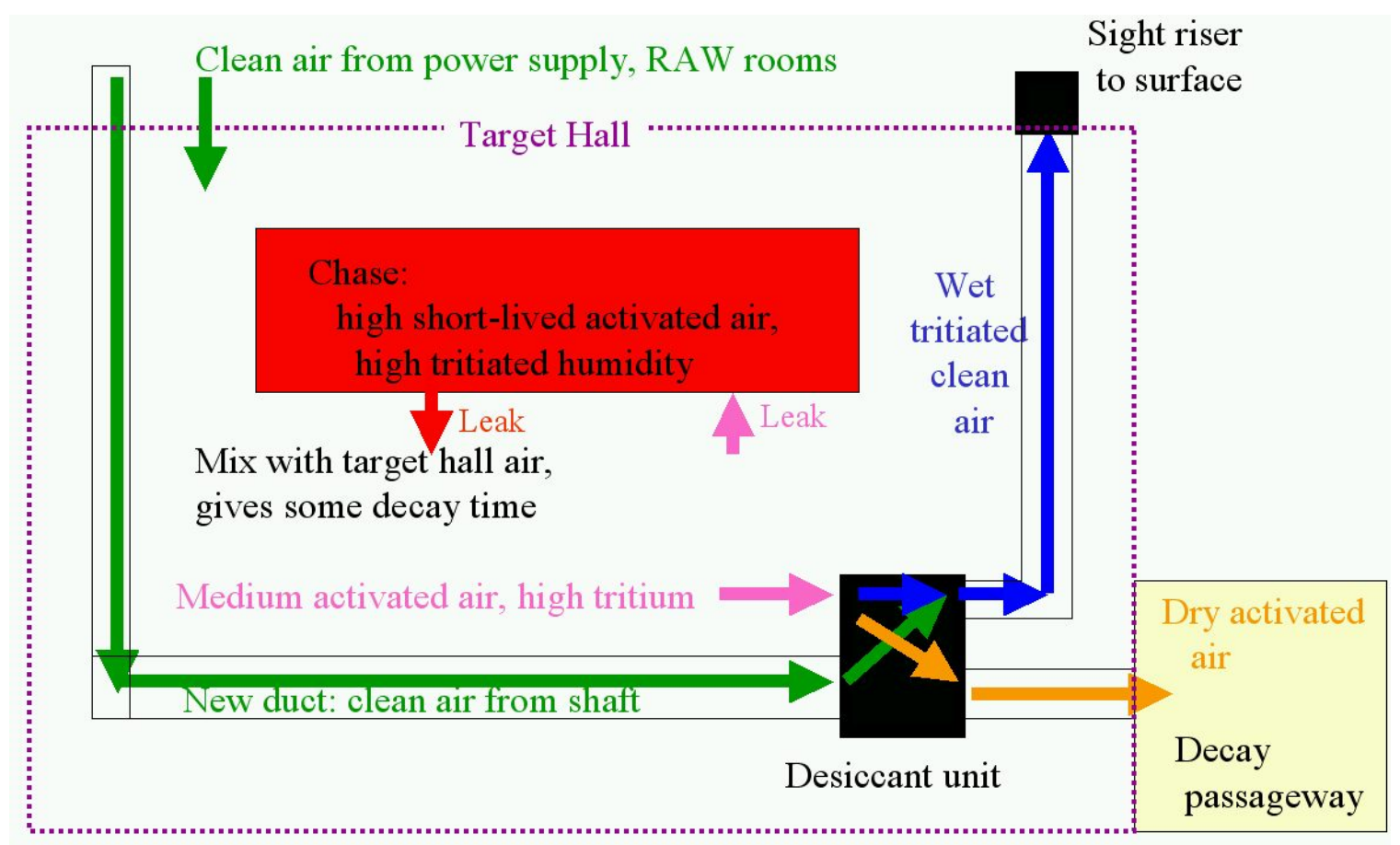

Figure 5 Schematic of target hall air flows with desiccant dehumidifier unit. 

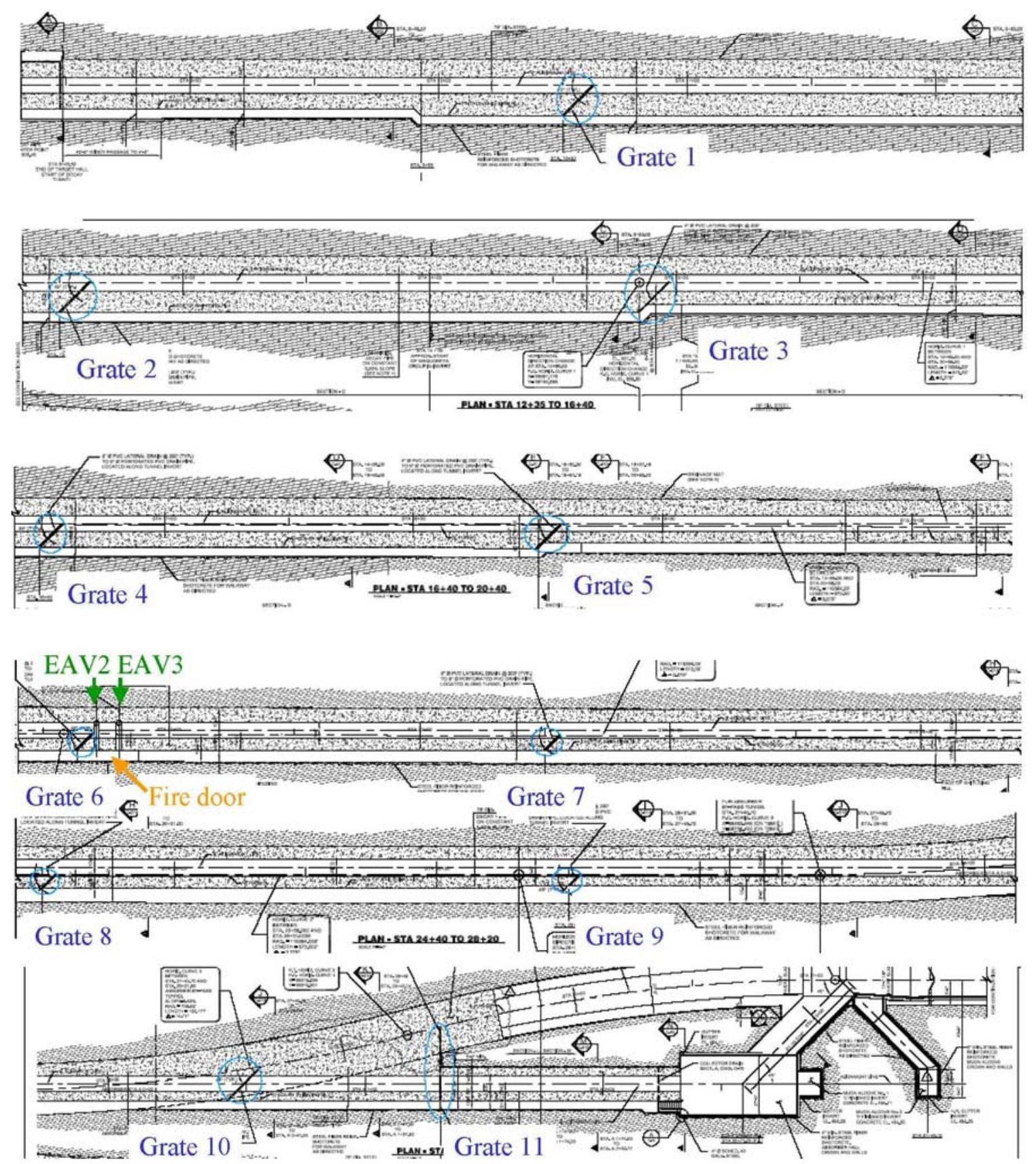

Figure 6 Decay pipe region: location of grates with drains from decay pipe walkway to main drain under decay pipe. Note the fire door, which separates two halves of the passageway between air vents to surface EAV2 and EAV3. 


\section{Estimate of tritium source in target hall humidity}

In this section we estimate the rate of tritium transported via humid target hall air for three running conditions. These conditions occurred during the initial year of running of the NuMI facility and the subsequent maintenance shutdown of the Fermilab accelerators.

(i) Beam-on condition. In early 2006, the water that the cooling coils condensed out of the air stream recirculating inside the target shielding had a tritium content averaging around 73,000 pCi/ml. About 47 to 50 gallons of this water was collected per day, accumulating a total of about $0.013 \mathrm{Ci} /$ day.

During commissioning of the target hall, the leak rate of air from the target shielding was measured with SF6 tracer gas to be $577 \mathrm{cfm}$ (2/17/05); this measurement was repeated in May 2006 with similar results. (This is out of a total recirculation air flow of 25,000 $\mathrm{cfm})$. The humidity content was of order 60 grains/lb during beam running conditions (target hall air averages about 66 deg F, 63\% relative humidity, 53 deg F dew point). For convenience of considering tritium transport, these values can be expressed as $0.29 \mathrm{ml}$ of water per $\mathrm{ft}^{3}$ of air. Using the above leak rate, one calculates that 64 gallon / day of water was leaving the chase as humidity into the target hall. We assume that this humidity carried the same concentration - 73,000 pCi/ml - of tritium as was condensed out by the chiller coil. It then mixed and diluted with target hall air, which was supplied from the power supply room penetration, the RAW water utility room penetration, and a plenum through the labyrinth that supplied air via the shaft from the surface.

Measurements of air exhausting from the target hall are as follows: 1000 to $1300 \mathrm{cfm}$ flowed into the decay pipe passageway, where it proceeded downstream and then to the surface through a penetration called EAV2; of order $100 \mathrm{cfm}$ was leaking to the pretarget area, which then flowed upstream and exhausted to the surface through a penetration called EAV1; of order $100 \mathrm{cfm}$ was leaking back to the shaft region. (See Fig. 2 for layout of these areas). Thus the $577 \mathrm{cfm}$ of air being pulled back into the target pile recirculating air system would consume 1/3 of the 64 gallon/day of the tritiated water, leaving an estimated 43 gallons/day (0.012 Ci/day) to be dispersed with the air flow. After mixing, the air would be estimated to have of order 21,000 pCi/ml-H2O. Some of the tritium should be plating out in the target hall walls. For the plots shown later in this note, it was assumed that about $16,000 \mathrm{pCi} / \mathrm{ml}-\mathrm{H} 2 \mathrm{O}$ made it to the start of the decay pipe passageway (based partly on dehumidifier samples taken in early April, as shown in Figure 7).

(ii) Beam-off fan-off condition. During the beam-off period of 3/23/06 to 3/30/06, air flow to the decay passageway was increased to about $3000 \mathrm{cfm}$, and the target hall humidity level dropped to $51.6 \% \mathrm{RH}$ at $65.1 \mathrm{deg} \mathrm{F}$, corresponding to $0.23 \mathrm{ml}$ water per $\mathrm{ft}^{3}$ of air. The target pile recirculating air system and chiller were turned off, so the 577 cfm forced air leak rate from the target chase was eliminated. However, some shielding was removed during this period, and natural convection could carry some air away from the chase region. A small dehumidifier was placed in the downstream part of the target hall, and samples of the water it condensed yielded around 3,000 $\mathrm{pCi} / \mathrm{ml}$ of tritium 
(Figure 7). We used this value as an initial condition for the model at the start of the decay pipe passageway. The fact that the tritium level did not go to zero after the beam turned off is attributed to diffusion from target pile concrete and steel, but is not completely understood at this time.

(iii) Beam-off fan-on condition. As a test, the target pile recirculation fan was turned back on from 4/7/2006 to 4/14/2006. As seen in Figure 7, this caused a substantial increase in the tritium concentration sampled by the target hall test dehumidifier, as well as in the tritium concentration measured in water pumped from the NuMI collection sump to an above-ground holding tank, which dropped again after the fan was turned off. The presumption is that the recirculating air system is pulling tritium from a target pile reservoir (concrete, steel, etc.). For the model graphs shown later, the humidity at the start of the decay pipe was set to $17,800 \mathrm{pCi} / \mathrm{ml}$ based on the test dehumidifier samples.

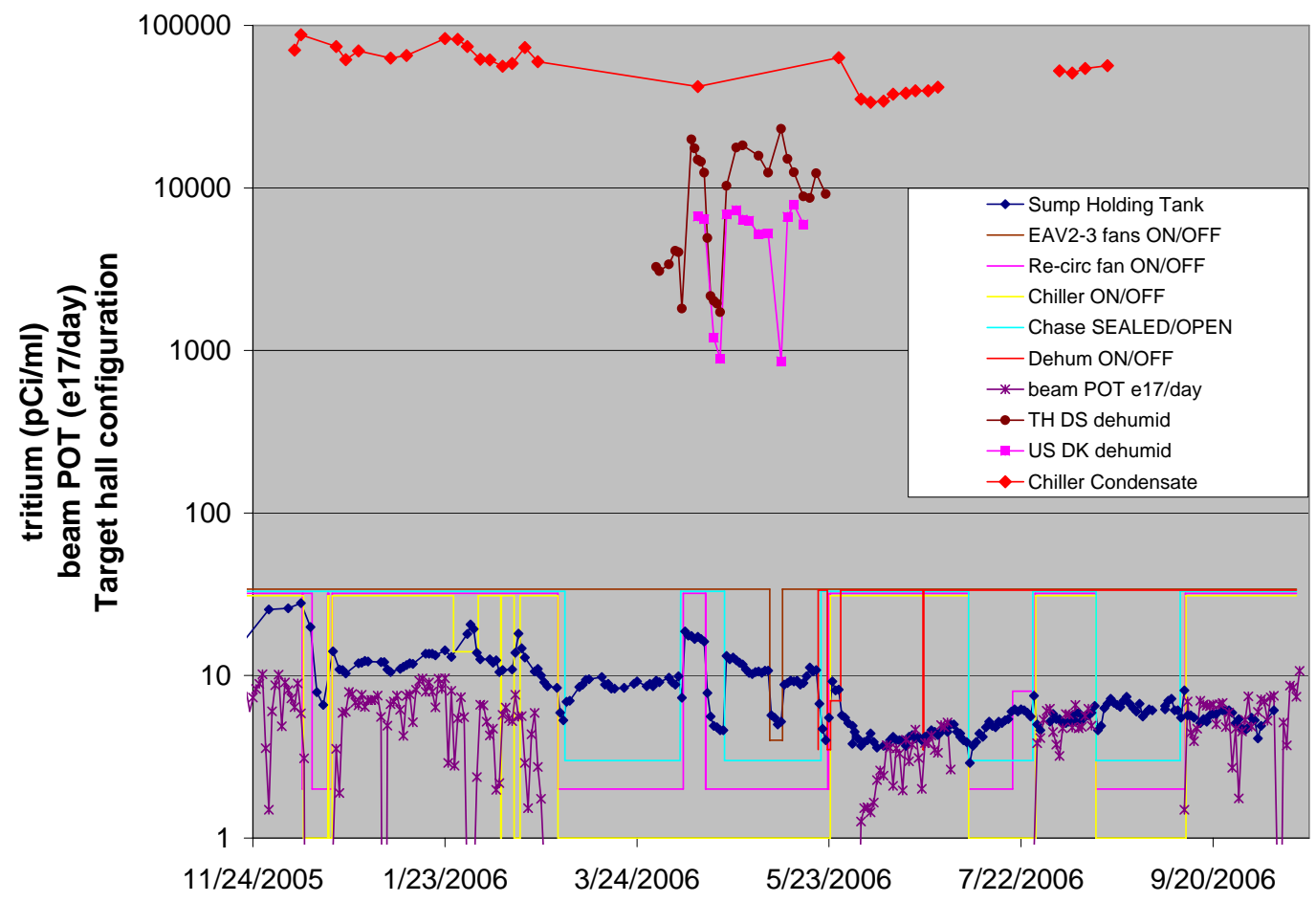

Figure 7 Tritium concentration in sump holding tank, chiller condensate tank, and samples from test dehumidifiers as a function of time, overlayed with target hall configuration and beam protons on target. 


\section{The CHAFT model}

The CHAFT model was developed to quantitatively explain the levels of tritium measured as a function of distance along the decay passageway. For much of the passageway, the relative humidity is $100 \%$, a large fraction of the wall area is damp, and the air temperature is approximately constant. In such a case, bulk H20 deposition does not occur, but exchange at the molecular level from the high tritium-concentration air to the lower tritium-concentration wall dampness can still be significant.

We used simple assumptions for the calculation. The damp surface is assumed to be at much lower tritium concentration than the humidity, and the deposition of tritium onto a surface is assumed to be proportional to $\mathbf{C}$ (concentration of tritium in water making up the humidity, $\mathrm{pCi} / \mathrm{ml} \mathrm{H20}$ ), $\mathbf{H}$ (humidity level, $\mathrm{ml} \mathrm{H} 20 / \mathrm{ft}^{3}$ air), A (area of wall, $\mathrm{ft}^{2}$ ), $\mathbf{F}$ (fraction of wall area that is damp, \%), and $\mathbf{T}$ (time, minutes). The model then has a single free parameter, $\mathbf{k}$ (deposition constant, $\mathrm{ft} / \mathrm{min}$ ). In summary:

\section{tritium deposited onto surface $(\mathrm{pCi})=\mathrm{k}$ CHAFT}

To estimate the order of magnitude of $\mathrm{k}$, we can take a data point from "Tritium Sorption on Concrete Protective Coatings and the Impact on Operational Safety” J.M.Miller, L.L.Deschenes, and J.A.Senohrabek, Journal of Fusion Energy, Vol 12 Nos 1/2, 1993. In that reference it was found that concrete absorbed $152 \mathrm{mCi} / \mathrm{m}^{2}$ in 4 hours from 10 $\mathrm{mCi} / \mathrm{m} 3$ tritium concentration in air at $5 \% \mathrm{RH}$, corresponding to $\mathrm{k}=0.21 \mathrm{ft} / \mathrm{min}$ in the CHAFT model.

For the rest of this note, the dampness fraction is left as $\mathbf{F}=\mathbf{1}$, and $\mathbf{k}=\mathbf{0 . 1 3} \mathbf{f t} / \mathbf{m i n}$ is used, which appears to fit the concentration data obtained in open pails reasonably well. (See below for further discussion.)

The dimensions of the decay pipe passageway were modeled as width $\mathbf{w}=\mathbf{5} \mathbf{f t}$, height $\mathbf{h}$ $=\mathbf{2 5} \mathbf{f t}$, and $\mathbf{L}=\mathbf{2 0 0} \mathbf{f t}$ between drain grates (measurement points, Figure 6).

The air flow rate through the decay pipe passageway during the time of this study was $\mathbf{f}=$ $1200 \mathbf{~ c f m}$ when beam was running and $\mathbf{3 0 0 0} \mathbf{~ c f m}$ when beam was off and the NuMI target hall was open for access.

The air flowing down the decay pipe passageway, after an initial transition region, is essentially at a constant temperature and $100 \% \mathrm{RH}$. For this case, integrating the tritium deposition as air flows down the decay passageway then yields the relation

$$
C_{n+1}=C_{n} \exp (-2(w+h) L F k / f)
$$

between concentrations at the $(n+1)$ measurement point and the $n^{\text {th }}$ measurement point. 


\section{Measurements in decay passageway}

At the grates (drains) along the decay pipe passageway shown in Figure 6, we measured the flow rate of water into each drain, along with the concentration of tritium in the drain water. (See table 1. Futher details on the measurements of flow rates in the decay pipe drains may be found in Appendix B.). In addition, a pail with a liter of water was placed next to each grate, and the tritium concentration was measured in the water after a certain exposure time.

The drain measurements give the contribution of each section of decay pipe passageway to the MINOS sump water, and the pail measurements give a check of humidity deposition of tritium. Water in sealed bottles placed near the pails yielded negligible tritium, so direct production of tritium in the pails can be neglected.

Calculation of tritium flow in drain measurements is illustrated by the simple multiplication in Table 1. Calculation of the model for comparison to pail, data is done using $\mathbf{C}_{\text {pail }}=\mathbf{k} \mathbf{C H A F T} / \mathbf{V}$, where $\mathbf{V}=$ volume of water in pail $(\mathrm{ml})$. The pails had a water surface area of $\mathbf{A}=\mathbf{0 . 5} \mathbf{f t}^{2}$, and were left in place for time $\mathbf{T}$ between 1.7 and 7 days for different samples.

\begin{tabular}{|l|c|r|r|}
\hline $\begin{array}{r}\text { Date data } \\
\text { taken }\end{array}$ & 1/26/06 & \multicolumn{1}{c|}{$1 / 10 / 2006$} & \\
\hline & water flow & T concentration & Tritium rate \\
\hline & gpm & pCi/ml & pCi/ml * $\mathrm{g} / \mathrm{m}$ \\
\hline grate 1 & 2.20 & 109 & 239 \\
\hline grate 2 & 2.88 & 90 & 258 \\
\hline grate 3 & 2.14 & 56 & 120 \\
\hline grate 4 & 1.26 & 18 & 23 \\
\hline grate 5 & 0.43 & 25 & 10 \\
\hline grate 6 & 0.72 & 7 & 5 \\
\hline grate 7 & 0.28 & 58 & 16 \\
\hline grate 8 & 0.80 & 89 & 71 \\
\hline grate 9 & 0.00 & 181 & 0 \\
\hline grate 10 & 0.04 & 130 & 5 \\
\hline grate 11 & 0.16 & 195 & 31 \\
\hline Sum & 10.90 & & 779 \\
\hline
\end{tabular}

Table 1Tritium flow in water into grates in decay passageway. This accounts for about $37 \%$ of the $12 \mathrm{pCi} / \mathrm{ml} * 177 \mathrm{gpm}$ of tritium going to the MINOS sump.

\section{Comparison of model with data}

Figure 8 and Figure 9 show the comparison of the concentration of tritium measured in the pail water with the CHAFT model. Similarly, Figure 10 and 11 show the comparison 
of the tritium flowing down the decay pipe passageway grates compared to the predictions of the CHAFT model, where the implicit assumption is that all the tritium deposited is being carried out by the water rather than building up in the walls.

The one free parameter in the model, $\mathrm{k}$, determines how fast tritium is depleted out of the air, and manages to simultaneously roughly account for (i) the absolute deposition rate in the pails, (ii) the slope of the exponential drop-off of deposition in pails along the decay passageway, (iii) the change in slope of the deposition in pails along the decay passageway when the air flow rate increased during beam-off conditions, (iv) the absolute tritium flow rate in the grate water, and (v) the fall-off along the decay passageway of the tritium concentration in grate water.

The grate 1 data point in Figure 10 is subject to two effects, both of which can help explain why its result is low relative to the model. First, there is a periodic flushing of water through that area by a discharge from the target hall shaft elevator sump pump (approximately every 15 minutes). The water flow rate and tritium concentration were measured between flushes, but some tritium will be washed away by the flushing. Secondly, we hypothesisze that some of the tritium makes its way to the under-drain by either (a) seaping through cracks between the wall and sidewalk and/or (b) condensing in the air space over the concrete shielding (which is not insignificant) and making its way down the other side of the shielding. That speculation gained experimental support when it was seen that cutting off the flow of tritiated humid air through the decay passageway significantly reduced the tritium concentration in the main drain coming from upstream of grate 1 . (We measure the main drain concentration by temporarily blocking the flow of water into grate 1, and using a long tube to draw a sample of water from the main drain at that location).

\section{Addition of desiccant dehumidifier}

Desiccant dehumidifiers were installed in May 2006 to reduce the humidity of target hall air which reaches the decay pipe passageway. The 5 desiccant units are manufactured by Munters, Inc., and utilize a regenerable silica gel desiccant. The units absorb humidity onto the gel and then expel it from the gel into an exhaust system, in this case the sight riser SR3 which is used to vent the tritiated water vapor to the atmosphere above ground. The units operate continuously, dehumidifying the air before it enters the decay pipe tunnel access passageway.

Including a correction for the grate 1 tritium flow point as discussed above, from the CHAFT model one expected about a factor of two reduction in the holding tank tritium concentration from this modification. This is about what has been achieved (e.g. compare January 2006 with September 2006 in Figure 7). 


\section{Conclusion}

The simple CHAFT model reproduces the dominant features of the tritium measurements from the upstream half of the decay pipe passageway, both in magnitude and distribution. It successfully fills the purpose of quantitatively matching target hall humidity to the decay pipe passageway transport of tritium to the MINOS holding tank water. 


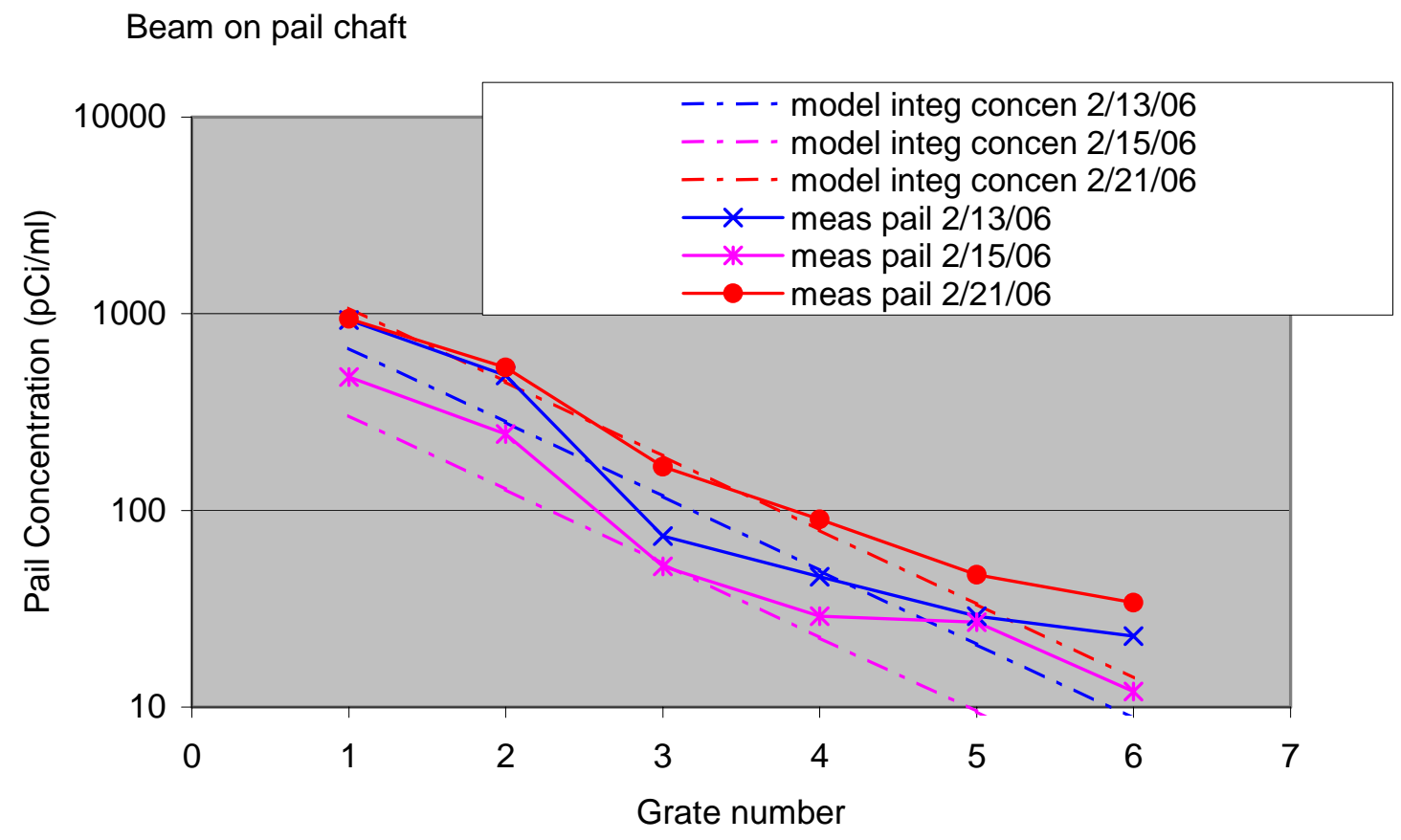

Figure 8 Tritium concentration in pail water compared with CHAFT model for standard beam-on air flow conditions.

Chaft model pail beam off

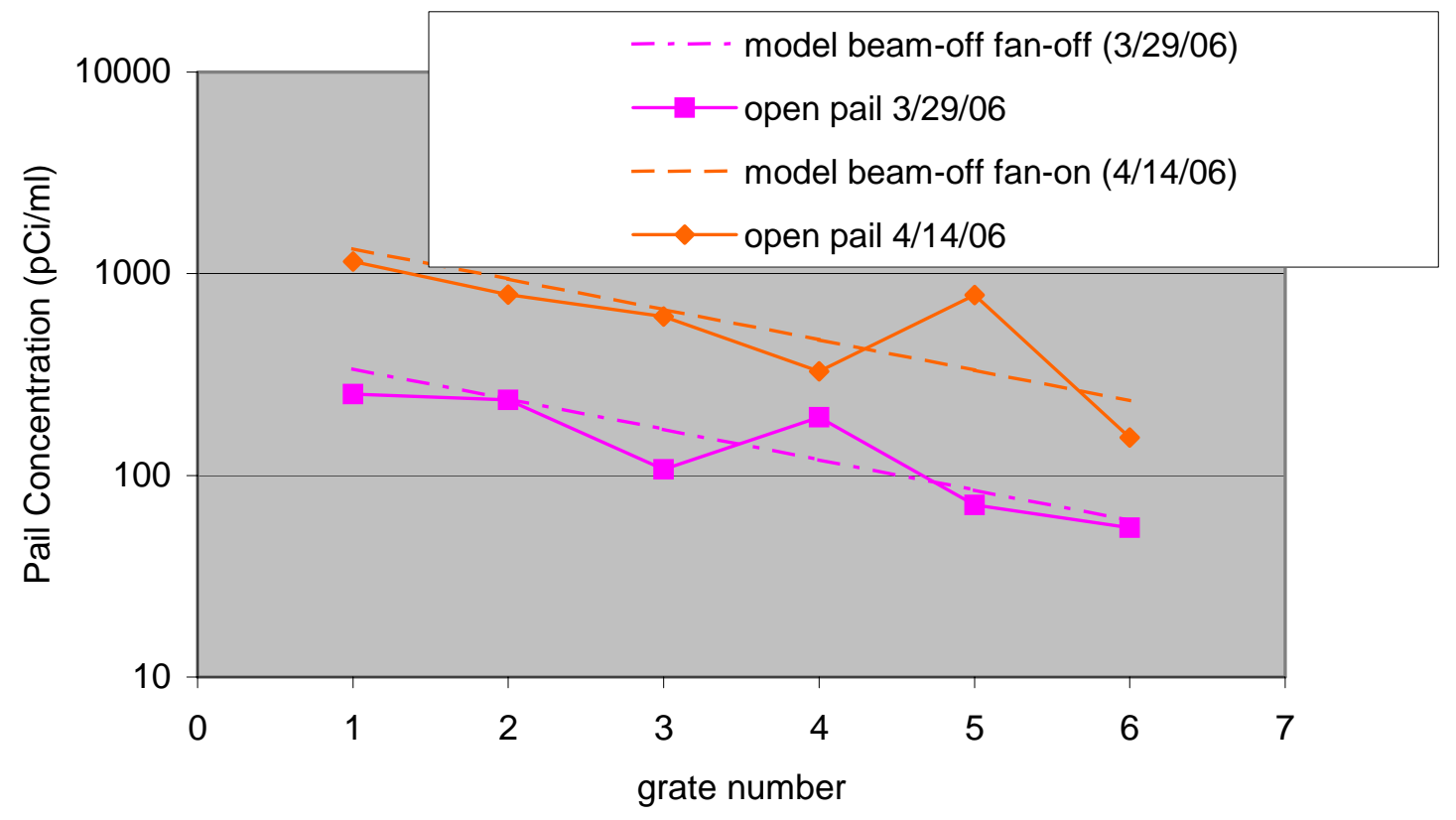

Figure 9 Tritium concentration in pail water compared with CHAFT model for beam-off air flow conditions. 


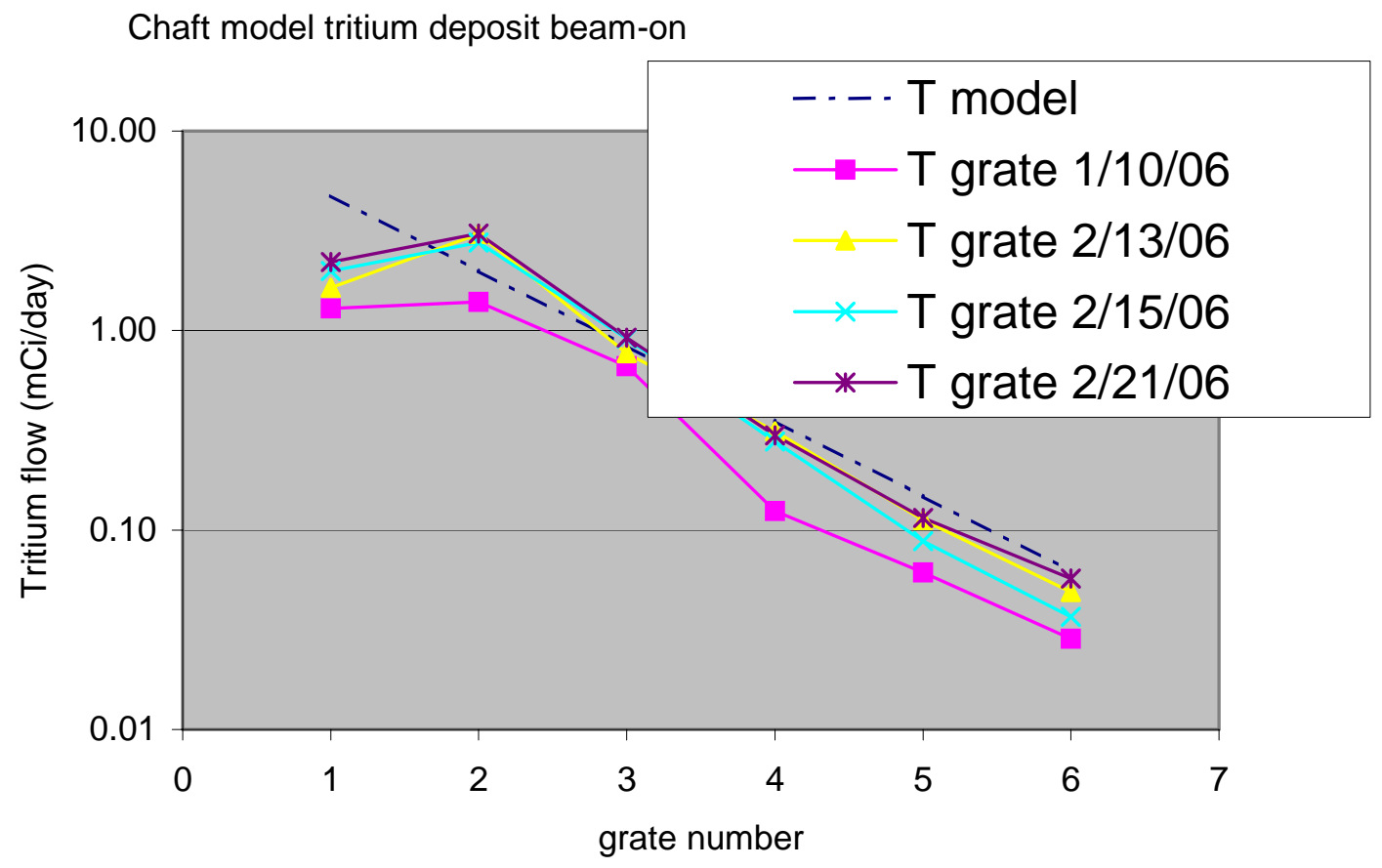

Figure 10 Measurements of tritium flow (tritium concentration times water flow rate) compared to CHAFT model for beam on conditions.

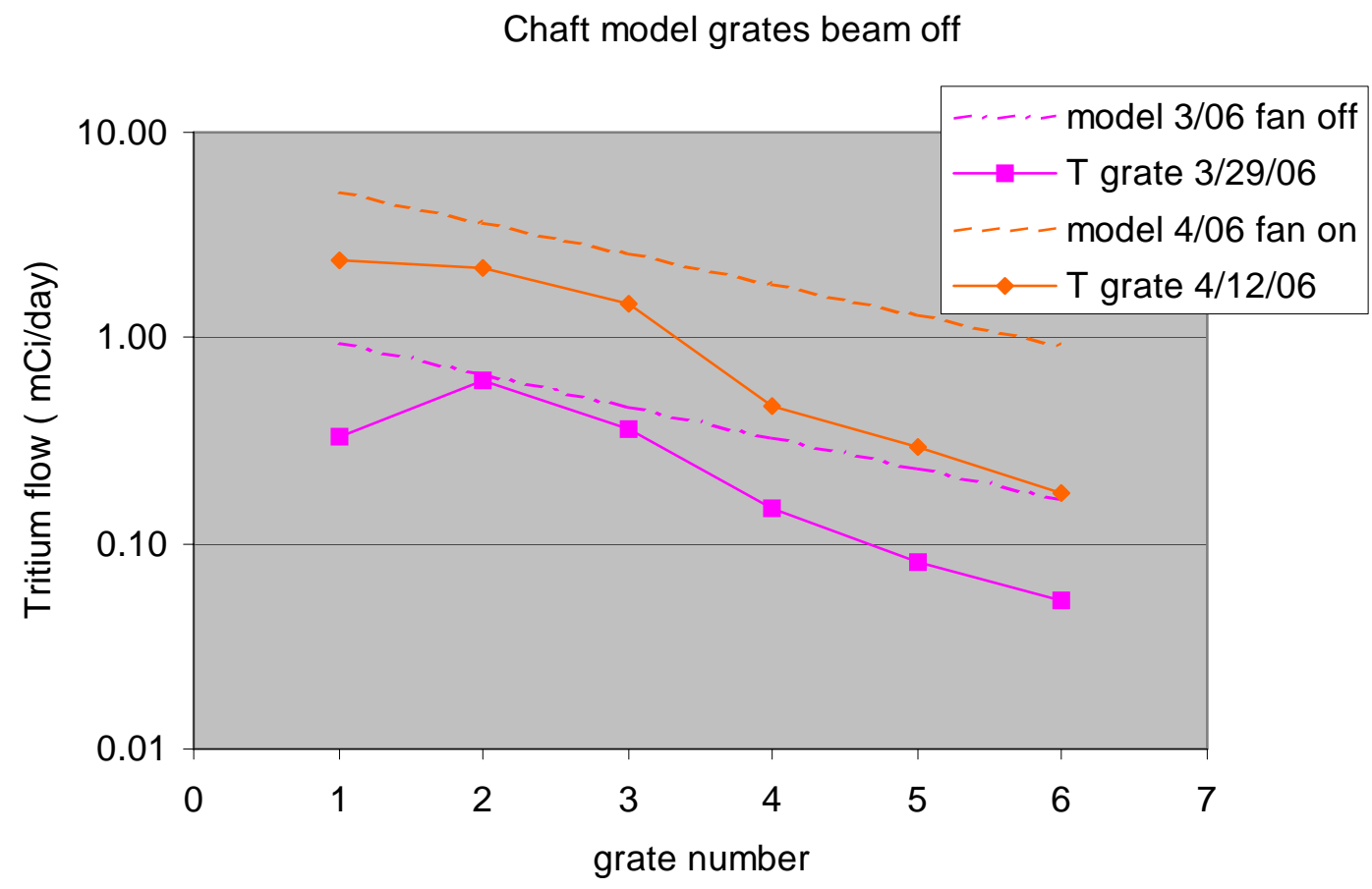

Figure 11 Tritium flow (tritium concentration times water flow rate) compared to CHAFT model for beam off conditions. 


\section{Appendix A: Modeling of Tritium Rate with Recent Running Conditions.}

In this appendix, we present a recent overview of recent tritium measurements, and discuss a simple empirical model which describes these measurements accurately. Figure A1 shows measurements of the tritium concentration in the sump holding tank and the concentrations measured in the water removed from the recirculating chase air by the chiller system. The two sets of measurements show good agreement in shape, which helps us confidently state that airborne tritium in humid air is an important source of the tritium found in the holding tank. (The agreement in normalization of these two sets of measurements is a numerical coincidence.) The daily beam delivered to the NuMI target (POT) is also shown in figure A1, showing clear tracking of the tritium levels with beam intensity.

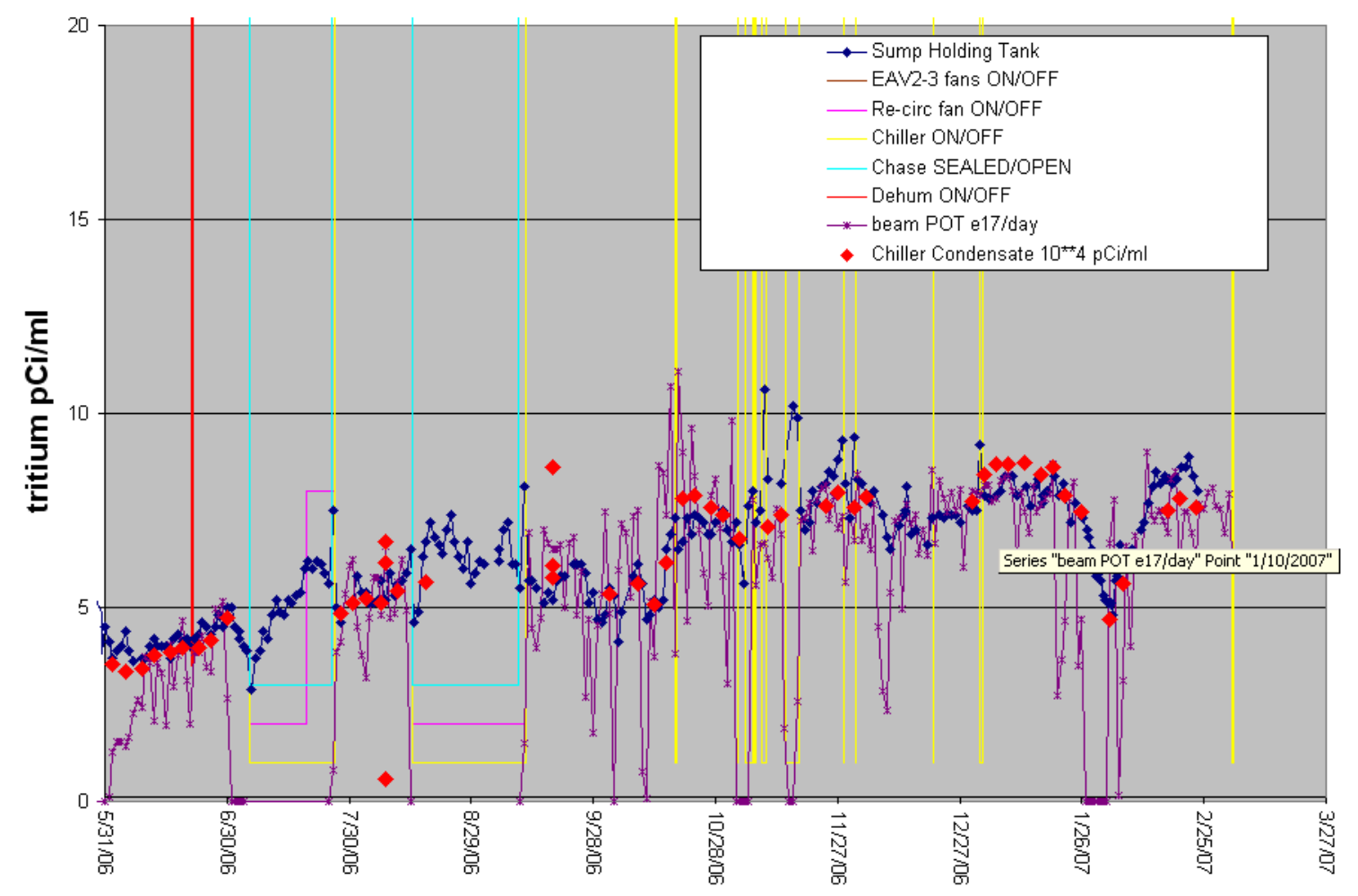

Figure A1. Measurements of holding tank and chiller condensate tritium since the 2006 accelerator shutdown. Also shown are lines indicating the configurational status of the target hall complex. In all cases, normal operating conditions are represented by lines in the upper position. 
We have compared the observed tritium levels with a simple formula which includes both a component of instantaneous (daily) intensity and a term which allows for a component depending on the total integral of delivered protons. The equation may be written as:

$$
C=R \sum_{i=0}^{n_{0}} N_{i} \Delta t+D \sum_{j=1}^{9} N_{n_{0}-j} e^{-j \Delta t / \tau}
$$

Where $\mathrm{C}=$ concentration in $\mathrm{pCi} / \mathrm{ml}, \mathrm{N}_{\mathrm{i}}=$ proton intensity per day in POT/day, $\tau=$ short-term tritium concentration decay constant in days, $\mathrm{n}_{0}=$ total number of running days, and $\Delta t=1$ day. $\mathrm{R}$ and $\mathrm{D}$ are constants in units of ( $\mathrm{pCi} / \mathrm{ml}$ ) / POT (for $\mathrm{C}$ ) and (pCi/ml)/(POT/day) (for D).

We adjusted the constants $\mathrm{R}, \mathrm{D}$, and $\tau$ to obtain agreement with the observed data. The values obtained are:

$$
\begin{aligned}
& \mathrm{R}=2.0 \mathrm{pCi} / \mathrm{ml} \text { per } 10^{20} \text { protons } \\
& \mathrm{D}=1.6 \mathrm{pCi} / \mathrm{ml} \text { per } 10^{18} \text { protons } / \text { day } \\
& \tau=3.5 \text { days }
\end{aligned}
$$

Note that for constant running conditions, the sum of exponentials in the second term in the above equation simplifies that term to $4.5 \mathrm{pCi} / \mathrm{ml}$ per $10^{18}$ protons/day.

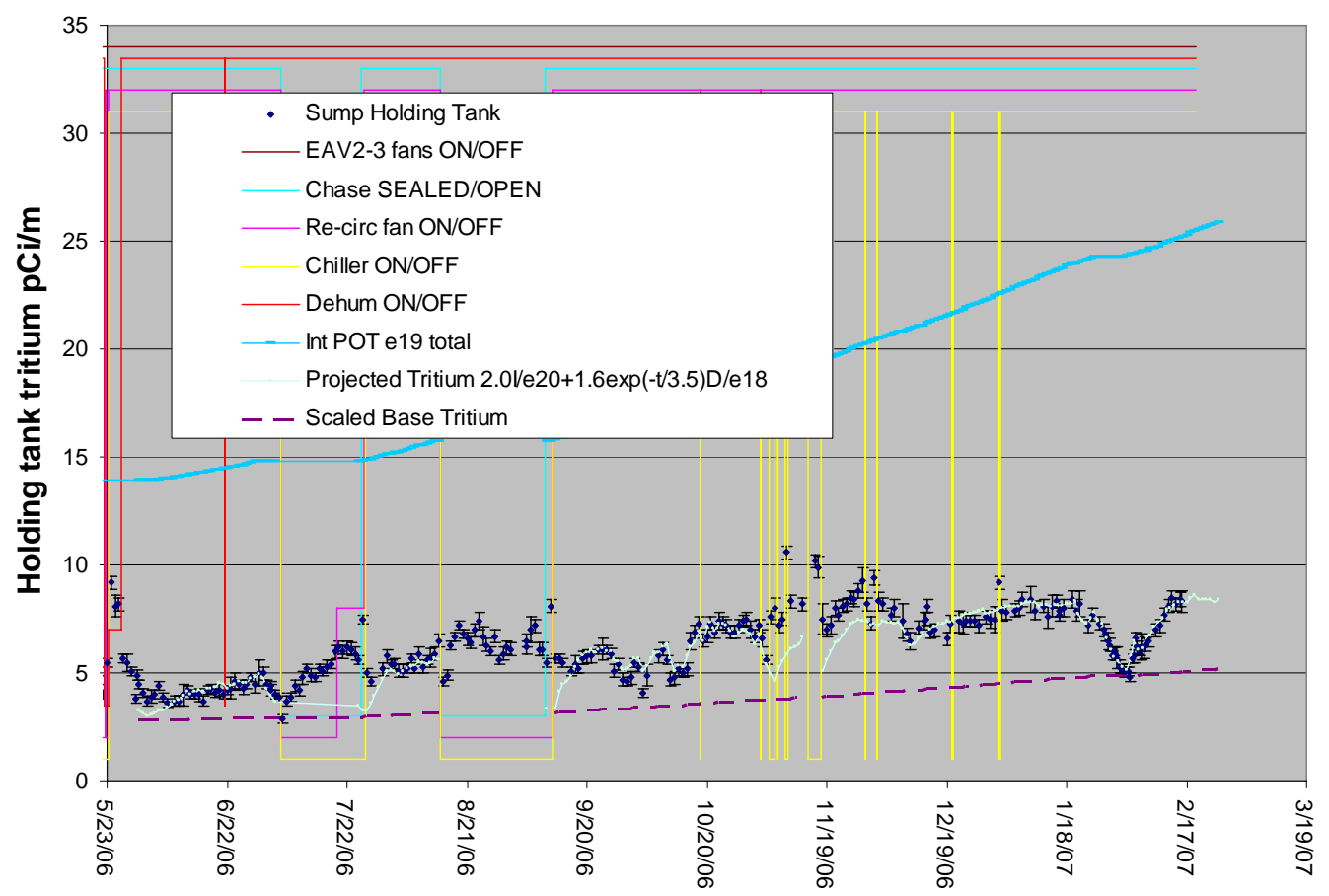

Figure A2: Tritium holding tank concentrations showing predictions of empirical model. 


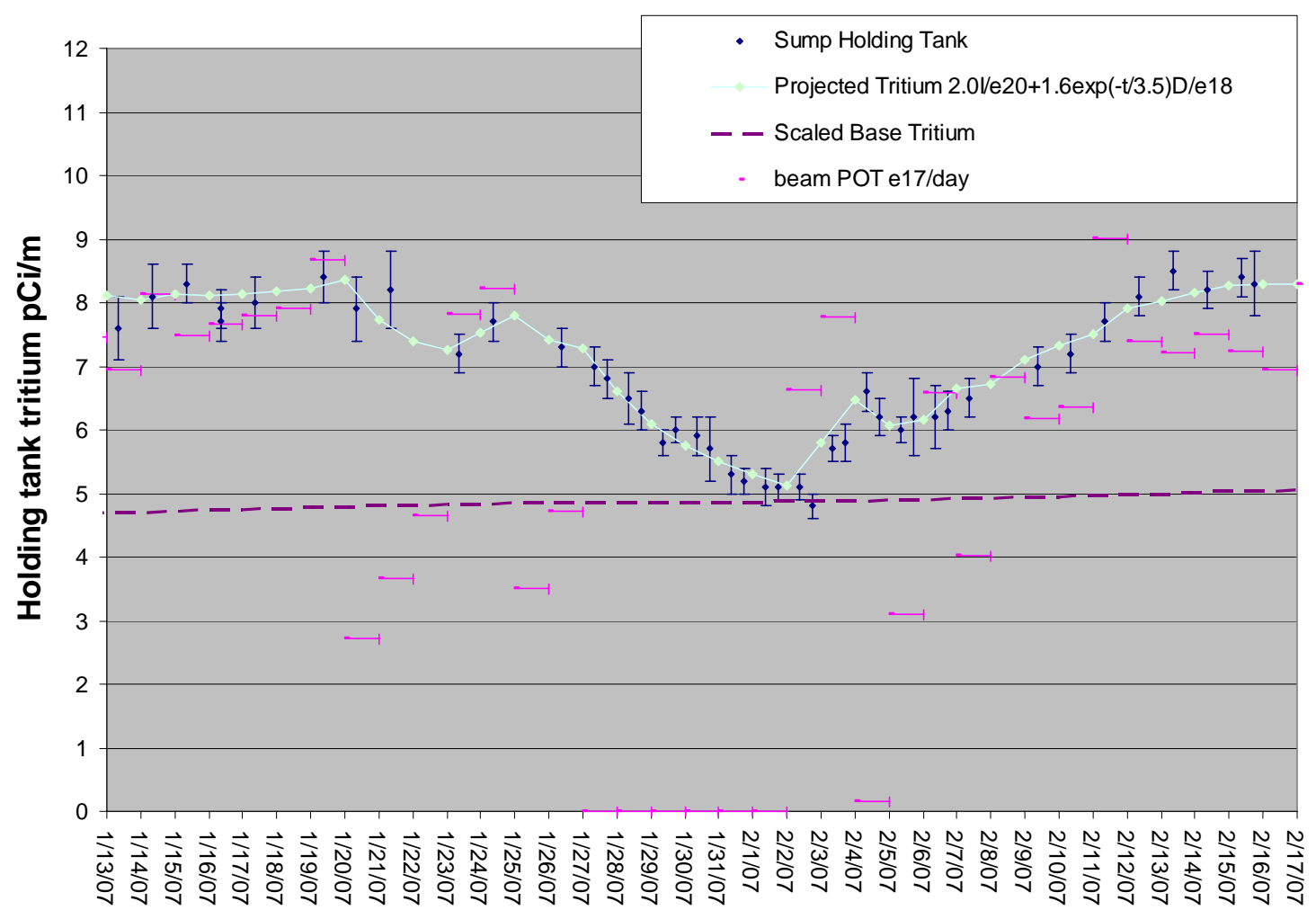

Figure A3. Tritium concentration on an expanded scale, showing the effects of short-term decay of the term associated with instantaneous intensity.

Figures A2 and A3 show the level of agreement between our model and the data. The line marked "Scaled Base Tritium" is the contribution of the first term of the model, representing the contribution due to integrated intensity. The level of agreement observed is good, and helps demonstrate that both integrated and instantaneous intensity are contributing to our observed tritium concentrations. 


\section{Appendix B: Measurement of water flow rate into NuMI Decay Pipe drain grates}

The technique utilized to measure flow rates in the NuMI grates is illustrated in Figures B1 and B2. The most recent measurement as of this writing was carried out by Jim Hylen , Hiep Le, and Cervando Castro on Feb1, 2007. The results are listed in Table B1, along with an estimate of the contribution of each drain to the total tritium collected in the MINOS sump.

Comparison with the two previous measurements of flow into the grates is shown in Figure B3. The first measurement was done by Jim trying to use a sink drain stopper to plug the pipe, and seepage past the stopper was a significant source of systematic error. (Two other early techniques did not work; a commercial drain plug was unworkable because of cement on the edge of the pipe, and an alternate technique which attempted to pump the water below the level of the drain pipe with a portable pump was also problematic). For the second measurement, Duane Plant, Bob Ducar and Evelyn Aponte developed the balloon technique, which works very well. 


\begin{tabular}{|c|c|c|c|c|c|c|c|c|c|}
\hline & & & & $2 / 1 / 2007$ & & flow & $11 / 2 / 2006$ & Product & relative \\
\hline & width & length & height & time & flow & & Concen. & flow times & contrib. \\
\hline & inch & inch & inch & seconds & $\mathrm{cfm}$ & gpm & $\mathrm{pCi} / \mathrm{ml}$ & concen. & to \\
\hline & & & & & & & & $\mathrm{pCi} /\left.\mathrm{m}\right|^{*} \mathrm{~g} / \mathrm{m}$ & sump \\
\hline \multirow[t]{2}{*}{ grate 1} & 47.5 & 6 & 0.75 & 24 & 0.31 & & & & \\
\hline & 47.5 & 6 & 0.75 & 28 & 0.27 & & & & \\
\hline Ave. & & & & & 0.29 & 2.15 & 37.5 & 81 & $7 \%$ \\
\hline \multirow{3}{*}{ grate 2} & 48 & 6 & 05 & 15 & 033 & & & & \\
\hline & 48 & 6 & 0.5 & 13 & 0.38 & & & & \\
\hline & 48 & 6 & 0.5 & 18 & 0.28 & & & & \\
\hline Ave. & & & & & 0.33 & 2.48 & 18.3 & 45 & $4 \%$ \\
\hline \multirow{3}{*}{ grate 3} & 18 & & 075 & & $0 ?$ & & & & \\
\hline & 48 & 6 & 0.75 & 34 & 0.22 & & & & \\
\hline & & & & & 0.23 & 1.70 & 9.9 & 17 & $1 \%$ \\
\hline \multicolumn{10}{|l|}{ Ave. } \\
\hline \multirow[t]{2}{*}{ grate 4} & 47 & 6 & 0.75 & 25 & 0.29 & & & & \\
\hline & 47 & 6 & 0.75 & 24 & 0.31 & & & & \\
\hline Ave. & & & & & 0.30 & 2.24 & 5.8 & 13 & $1 \%$ \\
\hline \multirow{2}{*}{ grate 5} & 48 & 6 & 0.75 & 60 & 0.13 & & & & \\
\hline & 48 & 6 & 0.75 & 67 & 0.11 & & & & \\
\hline Ave. & & & & & 0.12 & 0.89 & 11.1 & 10 & $1 \%$ \\
\hline \multirow{2}{*}{ grate 6} & 46 & 6 & 075 & 39 & 0.18 & & & & \\
\hline & 46 & 6 & 0.75 & 37 & 0.19 & & & & \\
\hline Ave. & & & & & 0.19 & 1.42 & 4.1 & 6 & $0.5 \%$ \\
\hline \multicolumn{10}{|l|}{ Firedoor } \\
\hline \multirow[t]{2}{*}{ grate 7} & 48 & 6 & 0.50 & 94 & 0.05 & & & & \\
\hline & 48 & 6 & 0.75 & 136 & 0.06 & & & & \\
\hline Ave. & & & & & 0.05 & 0.41 & 116 & 47 & $4 \%$ \\
\hline \multirow[t]{2}{*}{ grate 8} & 48 & 6 & 0.75 & 53 & 0.14 & & & & \\
\hline & 48 & 6 & 0.75 & 56 & 0.13 & & & & \\
\hline \multirow[t]{2}{*}{ Ave. } & & & & & 0.14 & 1.03 & 58.1 & 60 & $5 \%$ \\
\hline & & & & & & & & & \\
\hline \multirow[t]{2}{*}{ grate 9} & 46 & 6 & 0.75 & 218 & 0.03 & & & & \\
\hline & 46 & 6 & 0.75 & 225 & 0.03 & & & & \\
\hline Ave. & & & & & 0.03 & 0.24 & 262 & 64 & $6 \%$ \\
\hline \multirow[t]{2}{*}{ grate 10} & 48 & 6 & 0.75 & 77 & 0.10 & & & & \\
\hline & 48 & 6 & 0.75 & 77 & 0.10 & & & & \\
\hline Ave. & & & & & 0.10 & 0.73 & 131 & 95 & $8 \%$ \\
\hline \multirow[t]{2}{*}{ grate 11} & 48 & 6 & 0.50 & 386 & 0.013 & & & & \\
\hline & 48 & 6 & 0.50 & 428 & 0.012 & & & & \\
\hline
\end{tabular}




\begin{tabular}{|r|l|l|l|l|r|r|r|r|r|}
\hline Ave. & & & & & 0.01 & 0.09 & 170 & 16 & $1 \%$ \\
\hline & & & & & & & & & \\
\hline Sum & & & & & & 13 & & 453 & $40 \%$ \\
\hline & & & & & & & & & \\
\hline $\begin{array}{l}\text { MINOS } \\
\text { holding } \\
\text { tank }\end{array}$ & & & & & & 163 & 7 & 1141 & $100 \%$ \\
\hline
\end{tabular}

Table B1. Flow measurements; for grate 1 the two measurements were taken about 2 minutes and 10 minutes after the shaft elevator sump periodic flush came by.

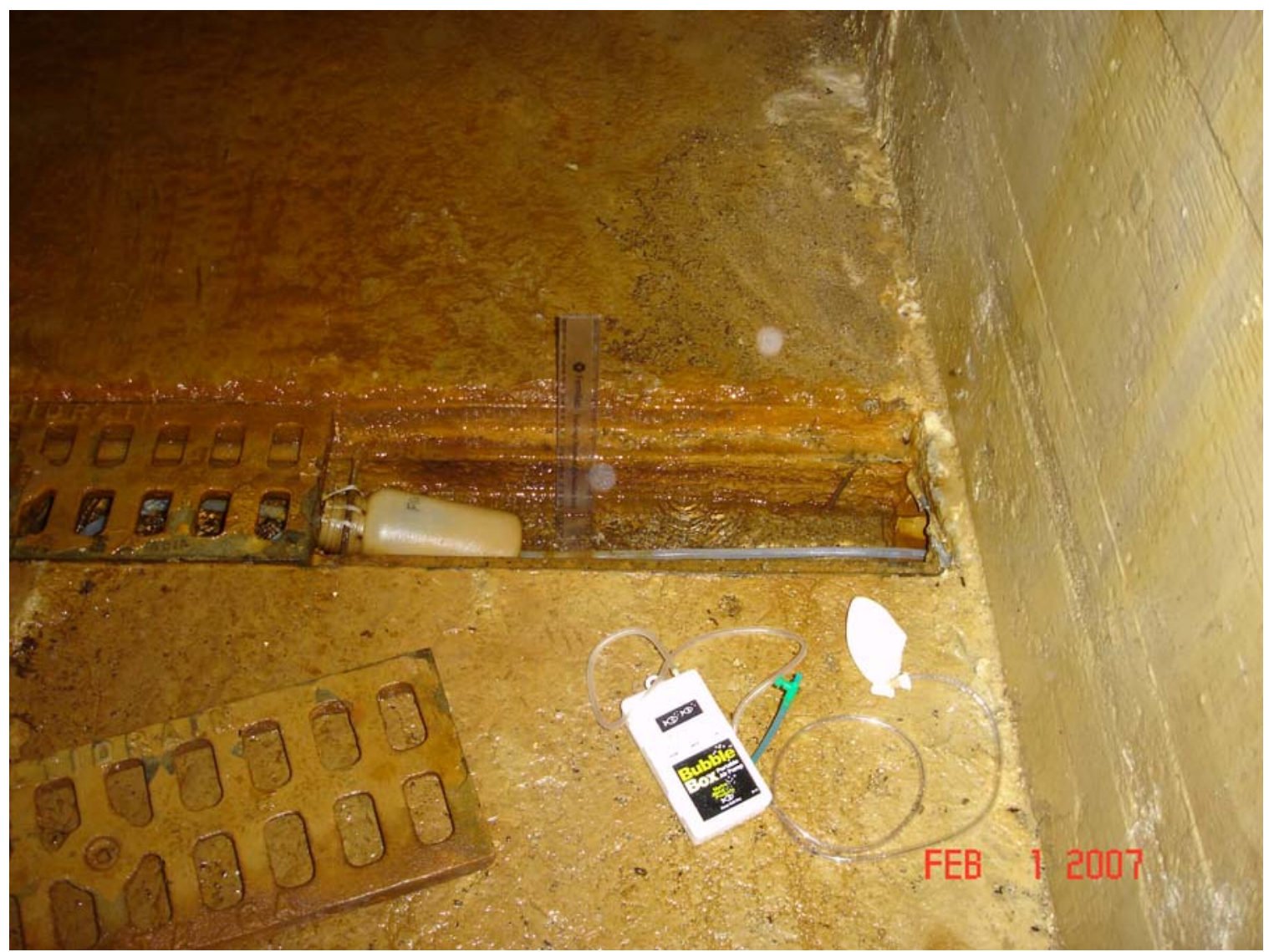

Figure B1. At Grate 1, the tube permanently installed for sampling the Main Drain is visible (but irrelevant). In the foreground is the air bladder for blocking the drain pipe in order to measure how fast the gutter fills up, and thus deriving the water flow rate. 


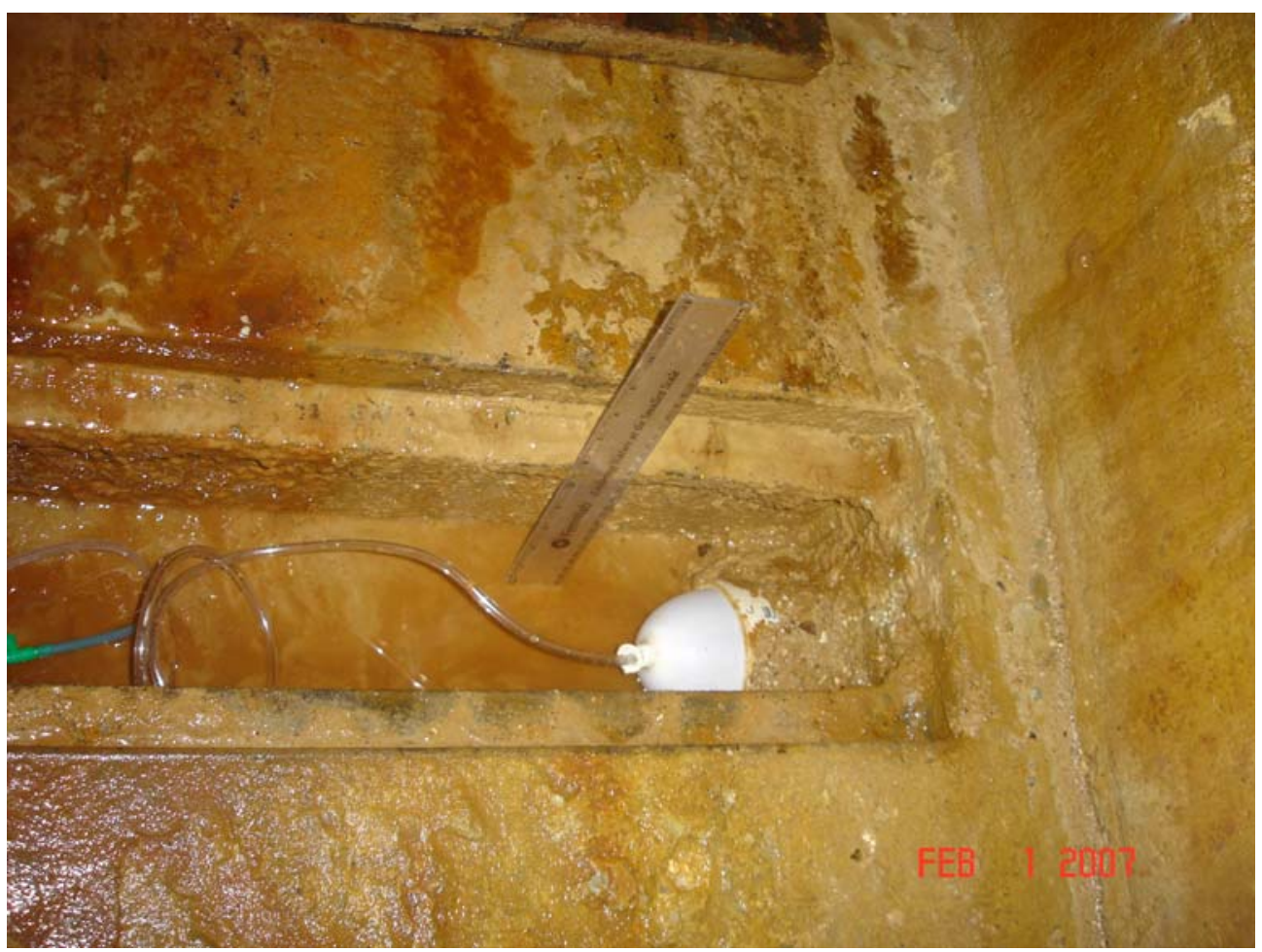

Figure B2. Air bladder blocking drain, and ruler for measuring increase in water height.

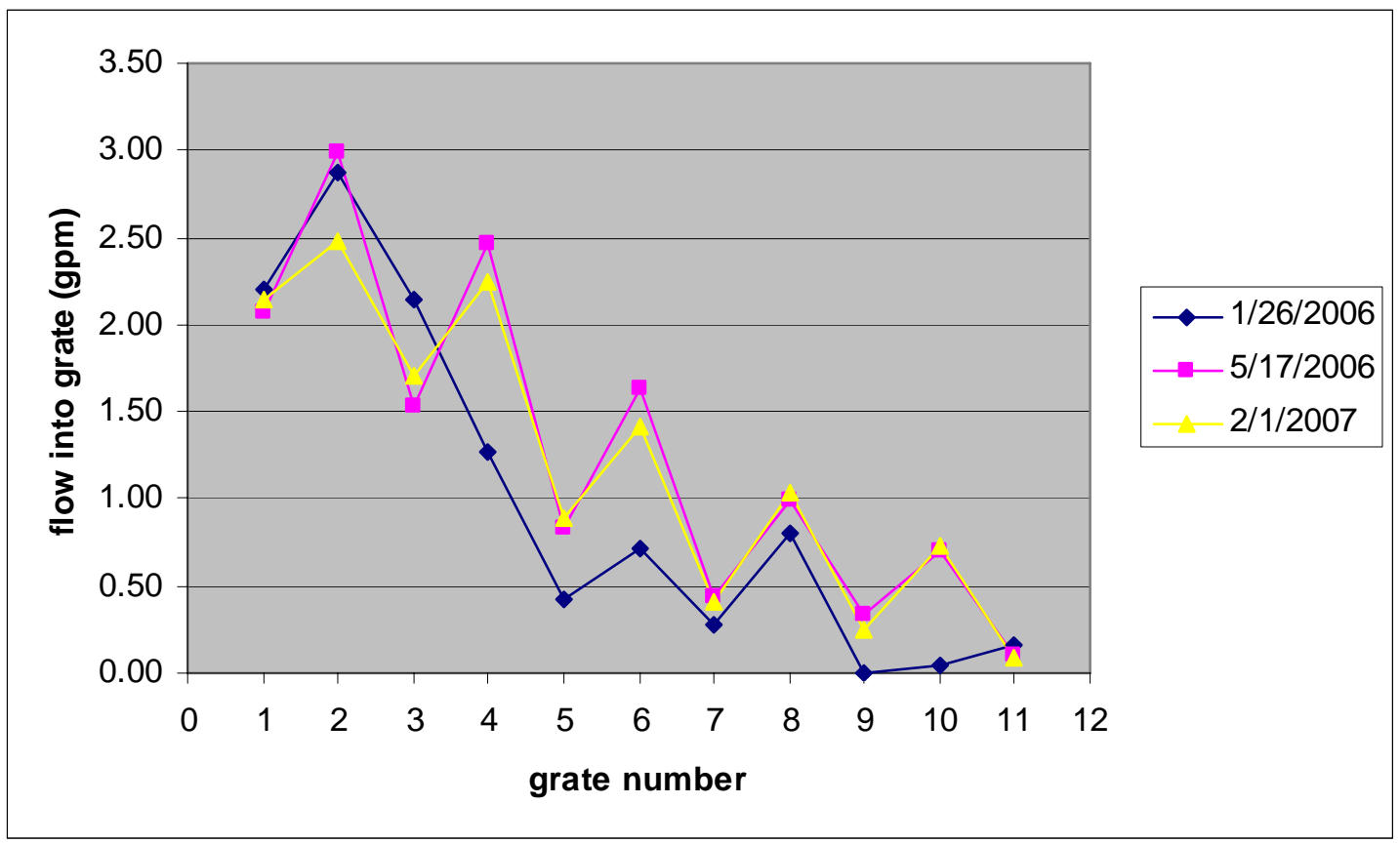

Figure B3. The three measurements made of water flow into Decay Pipe grates. 
